\title{
Same and Difference: Representations of Sexuality in Adolescents
}

\author{
Ziqi Wang \\ Department of Psychological and Behavioral Science, London School of Economics and Political \\ Science, London WC2A 2AE, United Kingdom \\ wangziqizq2015@163.com
}

Keywords: adolescents; representation; sexuality; context; knowledge encounter.

\begin{abstract}
Polybasic culture context and global flow of information are gradually overtaking traditional norms in shaping adolescent representations. The aim of this research is to understand adolescents' representations of sexuality. Compared to British-born Chinese, Chinese born - and raised adolescents represent similar norms; yet, their understandings and evaluations are relatively vague, resulting in a lack of appropriate guidance. With psychological inversion, adolescents resist vertical knowledge encounters; hence, it is better to make an effort to appeal to other less authoritative approaches instead of rigid sex and relationship education.
\end{abstract}

\section{Introduction}

Compared to ten years ago, adolescents tend to become mature earlier in both physical development and psychological preparation in sex, with their attitudes and behavior so more open (Hu, 2013). Apart from a younger age of first intercourse, more social issues - even crimes - occur. The development of the media, the internet and many other communication tools, as well as the condition that duty of 'gatekeeper' (Lewin, 1947) cannot be always executed, enables adolescents to gain access to a great deal of information that hasn't been filtered.

It is claimed that the characteristic changes in physical, psychological and social aspects make adolescents feel huge pressure as they transit from children to adults. (Wodarski and Harris1987). Among all the difficulties adolescents have to overcome, their own representations of sexuality are significant and crucial. Physical maturity leads to changes in their social and economic relations, as well as their psychological conditions. They may physically look like adults, yet it is the social, psychological and economics factors influencing each other that determine when the individual could become an autonomous adult. In this phase, adolescents come into contact with new knowledge and more complex issues; hence, the source and quality of new knowledge plays a crucial role in structuring their representations.

This research aims to discover how social context and knowledge encounter shape adolescents' representations of sexuality, especially intercourse. The research questions focus on the following segments:

How do adolescents present their representations, particularly in understanding and judging sexuality?

From what resources do they acquire their knowledge?

How do they communicate with different systems of knowledge?

Are there any distinctions between native-born and British-born Chinese? What causes these distinctions?

The rest of this article consists of three chapters. The first chapter describes the design of the study and the methods used to collect and analyze the data. The following chapter contains the findings from the analysis and the discussion of how these relate to overarching theories. The final chapter is the conclusion and suggestions for further research, as well as the limitations of this study.

A total of 400 participants, aged from 15-18 years, were selected as quota samples, and participated in the research as respondents. Quantitative data were analyzed by the SPSS program. 


\section{Methodology}

\subsection{Questionnaire design}

The questionnaire for this study was designed and modified between 12 April and 10 May 2016. The English version was put online on 12May and the Chinese version was released on 14 May. Because the participants live throughout China and the UK, an online questionnaire was the quickest and most effective method of reaching them.

The questionnaire consisted of nine questions, five to determine demographic information one to examine sex intercourse and residence status and three Likert-scale questions to examine the respondents' attitude distributions.

The research focus is on three aspects:

Communication conditions

Resources of knowledge

Judgment, evaluation and understanding of sexuality

The basis for setting these three segments is the self-other-object system of 'communication interaction forms' of representation. Individuals cannot form knowledge: we need an extended model of cognition that escapes from a lonely mind and enters the social and cultural world. The first segment is set to test how and to what extent knowledge is encountered through inter-individual communication. The second part examines the social and cultural context to which the respondents are exposed. The third part aims to find out the respondents' attitude distributions towards statements offering judgment on sexual intercourse, safe sex and sexual assault.

Using a Likert scale with closed questions generates statistical measurements of how people assess their assumptions and opinions on different aspects of sexuality. The data from the questionnaire was coded and entered into SPSS to be processed. Likert-scale scores are represented from strongly agree (coded with 5) to strongly disagree (coded with 1).

\subsection{Quantitative analysis overview}

All the questions in the questionnaire are compulsory. The respondent can go to the next question only if they have completed the current one. Therefore, there is no data missing from the 400 samples.

Data for the two research groups was drawn up in two-way tables and processed by SPSS. The full sample was divided into two parts according to respondents' growing environment. This search applied Pearson Chi-square test to examine the null hypothesis: The confidential distribution of attitude is the same for the BBC (Britain born Chinese) and CBC (China born Chinese) groups. The Pearson Chi-square test was applied because both the explanatory variable: growing environment and the reasonable variable: attitude measured in Likert Scale are categorical variables. Significance level is set at $\mathrm{p}<0.05$.The details of these statistical results will be explained in detail in the next chapter.

\section{Quantitative Research Finding}

As mentioned above in the methodology chapter, quantitative data were collected to indicate a basic distribution of respondents' attitude and formation of representation as well as the comparison between the two participant groups. The results from the questionnaire were later exported from the website where the survey was hosted in Chinese and in English, Quantitative data were then imported into SPSS for statistical analysis. The SPSS print outs can be found in Appendices. This section consists of two parts, an overview and significance test.

\subsection{Overview of Data}

On account of quota sampling method, the demographic characteristics were strictly controlled: 200 born and raised students with an even mix of boys and girls, aged from 15-18. The demographic distribution of 200 Britain born Chinese participants is the same.

Compared to the past research stated in the literature review, although CBC group hold a relatively traditional view on premarital sex than BBC group, it is apparent that CBC group participants feel far freer in sex than decades ago. Traditional Chinese moral regulation of virginity is being replaced by western representations about sexuality with a high speed (Figure 1). 


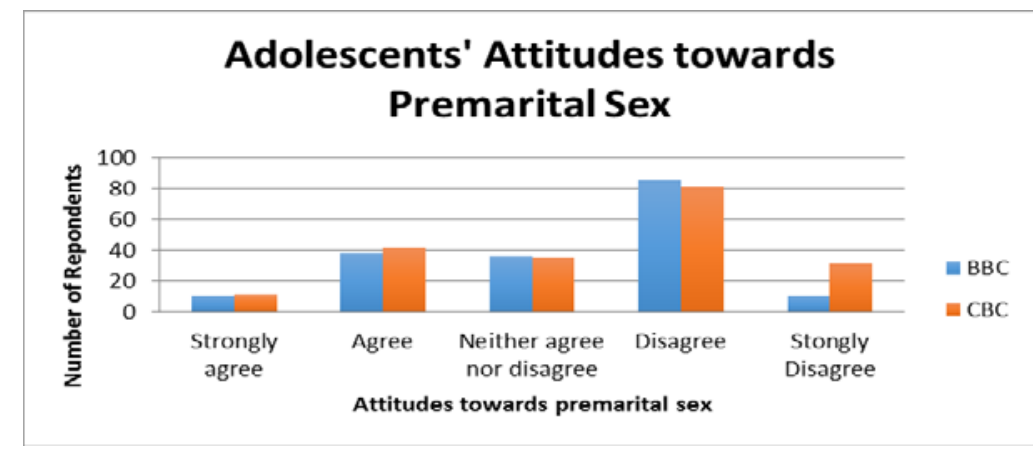

Figure 1 Adolescents' Attitudes towards Premarital Sex

An overall frequency of five pathways from which adolescents acquire knowledge about sex indicates that among all the sources of knowledge, Internet occupied the highest frequency. Meanwhile, the broken lines indicating how frequent teenager acquire sex education from TV and Books peaks respectively at 'occasionally' and 'sometimes'. We can infer from this result that, as a representative of traditional media, TV and books are not widely accepted by participants as a pathway to get access to sex education. Why adolescents tend to use new media to approach knowledge will be discussed in qualitative research segment (Figure 2).

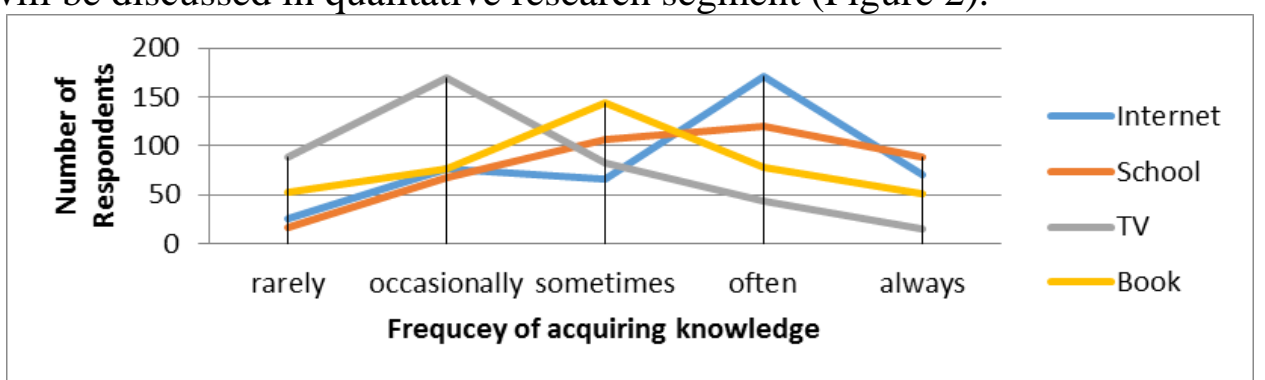

Figure 2 Five Pathways from which Adolescents Acquire Knowledge about Sex

'School' is different from the other three sources of knowledge. Information from Internet, books, and TV is alternative for audience, while in schools mostly the communication of knowledge is unidirectional. Hence, this frequency can be considered as an indicator for the non-optional social context the respondents exposed to. The result of chi-square test that examine whether the growing environment is associated with this element of social context will be discussed later.

Overall, the evaluation for two types of interpersonal communication reveals evident distinctions. For more than half of respondents, communicating with peers is more comfortable than talking about sex with parents. In the following text, the reason why participants hold this preference will be discussed in qualitative research part. And significance test will be applied to test whether adolescents grow in different environment express different ideas toward this issue (Figure 3).

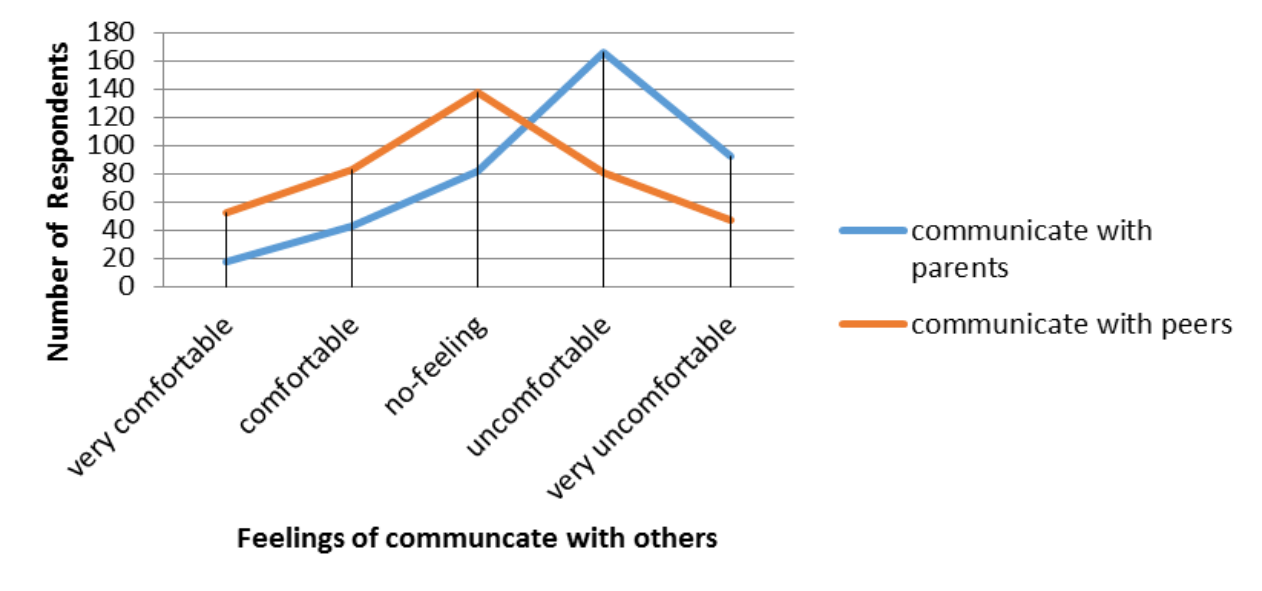

Figure 3 Adolescents' feelings of communicate with others about sex

Generally speaking, adolescents' preference of acquiring knowledge is within expectation. Also it can be predicted before that the adolescents' basic view on sexuality is tending to be more and more 
open-minded. In the next section, we will appeal to statistical approach to examine the association between variable factors.

\subsection{Significance Test}

As mentioned above, this research aimed to acquire a deeper understanding on how social context and, especially knowledge encounter shape adolescents' representations, significance tests were applied to examine the associations between respondents' growing environment and respondents' representations, as well as the formation of attitudes. In this research, the growing environment is X, and the attitudes, sources of knowledge and other variables measured in Likert Scale are denoted Y. Here the dichotomous $\mathrm{X}$ divides the full sample into two groups, identified by the observed value of $\mathrm{X}, \mathrm{BBC}$ and $\mathrm{CBC}$. Then this search counted these two groups as two separate samples, and considered statistical quantities separately for them.

To input results from Likert Scale into SPSS program, 'Strongly Agree' was coded to 5, and 'Strongly Disagree' was coded to 1 . In independent sample t-test, BBC group was defined as 1, and CBC group was defined as 2

The two categorical variables were drawn into a two-way contingency table. To examine if attitudes and group of residence associated with each other in population, chi-square test of independence was applied to test the null hypothesis: the two variables are statistically independent from each other. The results of significance test showed that $\mathrm{p}=0.658$, which indicated that the null hypothesis is not rejected. Hence we can draw a conclusion that, the respondents' attitudes toward the statement "Sex intercourse is common at my age" were uncorrelated with where they from. The views towards this basic question about sexuality are gradually tend to be the same among adolescents from different culture context as shown in table 1-3.

Table1 Group Statistics

\begin{tabular}{lccccc}
\hline & Group & $\mathrm{N}$ & Mean & Std. & Std. Error \\
\hline \multirow{3}{*}{ Norms of Sexualoty } & CBC & 200 & 3.45 & 1.115 & 0.079 \\
& BBC & 200 & 3.40 & 1.142 & 0.081 \\
\hline
\end{tabular}

Table 2 Significance Test of Norms of premarital sex between BBC and CBC Group

\begin{tabular}{|c|c|c|c|c|c|c|}
\hline & & \multirow[t]{2}{*}{$\mathrm{t}$} & \multirow[t]{2}{*}{$\mathrm{df}$} & \multirow[t]{2}{*}{ Sig. (2-tailed) } & \multicolumn{2}{|c|}{$\begin{array}{l}\text { 95\% Confidence Interval of } \\
\text { the Difference }\end{array}$} \\
\hline & & & & & lower & higher \\
\hline \multirow{2}{*}{$\begin{array}{l}\text { Norms of } \\
\text { Sexualoty }\end{array}$} & Equal variances assumed & 0.443 & 398 & $0 . .658$ & -0.172 & 0.272 \\
\hline & $\begin{array}{c}\text { Equal variances not } \\
\text { assumed }\end{array}$ & 0.443 & 397.762 & 0.658 & -0.172 & 0.272 \\
\hline
\end{tabular}

Table 3 Significance Test of status of using condom between BBC and CBC Group

\begin{tabular}{|c|c|c|c|c|c|c|}
\hline & & \multirow[t]{2}{*}{$\mathrm{t}$} & \multirow[t]{2}{*}{ df } & \multirow{2}{*}{$\begin{array}{c}\text { Sig. } \\
\text { (2-tailed) }\end{array}$} & \multicolumn{2}{|c|}{$\begin{array}{l}\text { 95\% Confidence Interval of the } \\
\text { Difference }\end{array}$} \\
\hline & & & & & lower & higher \\
\hline \multirow{2}{*}{$\begin{array}{l}\text { Attitudes towards } \\
\text { using condom }\end{array}$} & $\begin{array}{l}\text { Equal variances } \\
\text { assumed }\end{array}$ & $\begin{array}{c}5.57 \\
6\end{array}$ & 398 & 0.000 & 0.398 & 0.832 \\
\hline & $\begin{array}{c}\text { Equal variances not } \\
\text { assumed }\end{array}$ & $\begin{array}{c}5.57 \\
6 \\
\end{array}$ & $\begin{array}{c}397.76 \\
2 \\
\end{array}$ & 0.000 & 0.398 & 0.832 \\
\hline
\end{tabular}

Another statistical result strongly against the null hypothesis is understandings of using condom $(\mathrm{p}<0.001)$ and self-protection from sex assault $(\mathrm{p}<0.001)$. The result indicated that BBC participants hold more clear understanding on these two topics.

The chi-square significance test also indicated that the source from which the respondents acquire knowledge didn't examined to be related to where the respondents from in most of segments. Among various media platforms, Internet occupied the highest portion as the source of information. A significance distinction between the two groups displayed in the frequency of acquiring knowledge 
from school. The $\mathrm{P}$ value $<0.001$, indicating very strongly evidence against that access to knowledge in school and residence are associated in population. From this result, we can draw a conclusion that adolescents from both China and UK collect most of their knowledge about sex from the Internet. Given that UK Government has launched a policy to add sex and relationship education into secondary school schools, BBC participants acquire a relatively higher portion of knowledge from schools than CBC participants do. When proceeding qualitative research, this distinction was further explored.

\section{Conclusion and Discussion}

From the previous findings and results, we can conclude that an onslaught of information pushes adolescents to go through knowledge encounter earlier. Nowadays, adolescents are growing in an information explosion era. As the forth media, Internet is more friendly to audience than traditional media involving the press, movie and TV as everyone can be information promulgator, disseminator and embracer. Given that feature, we are now exposed to a great deal of information. Adolescents thus inevitably face knowledge encounters no matter where he or she leave because Internet gathers information from all over the word and spread it in a very fast speed. As adolescents just begin to collect knowledge more complex issues, it is very frequent for them to communicate with new systems of knowledge. Results from the frequent encounters of knowledge, adolescents begin to establish their own representation about sex much earlier than decades ago. Getting access to the Internet is an active process for collecting information. The standard of selection mostly depends on personal preference or what information seems to be interesting or accessible, hence it is difficult to guarantee the quality of information. Adolescents are in the phase that easily getting curious to new phenomena. Also, knowledge encounter between adolescents and information from the Internet is more personal and private than media because mostly adolescents use personal electronic devices to get connect to the Internet without restricted by time or space. It is difficult for the guardians to supervise their using of Internet. Though parents may not be pleased to acknowledge that their children untimely know too much about sexuality, it is inevitable that scattered, unfiltered information can easily reach adolescents. With the gradual collection of knowledge and will to be a real adult, adolescents are likely to conduct some social interactions though their accumulation of knowledge is not powerful enough to guide their behavior.

It is also apparent that adolescents' representations about sexuality are vague, even cannot be considered as a real sense of social representation. The knowledge adolescents have collected is unsystematic and scattered. Given the characteristics of online information, mostly what adolescents can acquire are short news, brief stories, or curt articles even some R-level movies. All those types of information are immethodical. Besides, with the timeliness of online information, a great deal of information is just simply edited before being released. Adolescents are not yet able to deal with what they accumulate from the Internet appropriate. It is difficult for them to structure different information systematically. Another fact is that the knowledge in adolescents' mind is fairly unstable. Sexuality is a brand new topic for adolescents. Initially, the encounter of knowledge is inputting. In the information age, opinion leaders' authority decrease, hence it is not easy for one voice to play a major role on media platform. In process of formation new representations, especially for adolescents, previous knowledge is likely to be replaced by a new one. One thing should be noted that, it is replacement of knowledge systems rather than conflict or negotiation. What' more, the unsystematic knowledge in adolescents' mind is not able to guide adolescents' social interaction? Mostly, what guide their behavior is their instinct or what they have seen from movies. Hence it cannot be regarded as a system of knowledge. It is better to say, adolescents are struggling to establish a representation on sexuality, but most of them only know a little unsystematic knowledge and a vague understanding.

Approach of knowledge encounter is particular meaningful at this period. Adolescents are going through a phase in which huge changes take place on both psychological and physical aspects. They may conduct some treasonous behavior to adults as they are eager to prove that they have grown up. Hence, communication between parents and adolescents becomes harder in this period. On one hand, 
they resist communicating with seniority on the other hand, they are not equipped to guide himself or herself appropriately. Being easily impacted may lead to the bias on behavior. Once resulting from some treasonous emotion they are more likely to take some views that against main public opinions. Given the factor that adolescents are inevitably undergo the knowledge encounter of sexuality, it's better for parents to guide than prevent it from happen. As rigid education may be strongly resisted, how to effectively convey meanings is a question should be taken into consideration. Also, although sex education from school only makes a limited effect on shaping the adolescents' representations, still it bring positive guidance to secondary school students. Formal and structured education could play a role in knowledge encounter. Sexuality is a normal problem very adolescent must face and has nothing to be ashamed of.

\section{References}

[1] Alexander, J. C. (1995). Fin de Siècle Social Theory. London: Verso.

[2] Allen, Eileen; Marotz, Lynn (2003).Developmental Profiles Pre-Birth through Twelve (4th ed.). Albany, NY: Thomson Delmar Learning.

[3] Crain, William (2011). Theories of Development: Concepts and Applications (6th ed.). Upper Saddle River, NJ: Pearson Education

[4] Duveen, G. (2001). Representations, identities, resistance. In K. Deaux \& G. Philogène (Eds.), Representations of the social (pp. 257-270). Oxford: Blackwell.

[5] Erikson, Erik H. (1993) [1950]. Childhood and Society. New York, NY: W. W. Norton \& Company. p. 242

[6] Hu. J (2013). Consequence of knowing nothing about Sexuality. Hongkong: Wenhui Press.

[7] Family Planning Association (2011).Sex and relationships education Fact Sheet. London: FPA

[8] Family Planning Association (2011). Teenagers: sexual health and behaviour Fact Sheet. London: FPA

[9] Gross, Francis L. (1987). Introducing Erik Erikson: An Invitation to his Thinking. Lanham, MD: University Press of America. p. 47.

[10] Howarth, C. (2002). Identity in whose eyes? The role of representations in identity construction. Journal for the Theory of Social Behaviour 32 (2), pp 145-162.

[11]Jovchelovitch, S. (2007). Knowledge in Context: Representations, Community and Culture. New York: Routldge

[12]Jovchelovitch, S. (2008). Trust and Social Representations: Understanding Relations between Self and Other in the Brazilian Public Sphere. In I. Marková and A. Gillespie (Eds.), Trust and Distrust, Sociocultural Perspectives (pp. 105-120). Charlotte, NC: Information Age Publishing.

[13]Jovchelovitch, S. (draft manuscript). Habermas's Theory of Communicative Action and the Dialogical Imagination. In D. Hook, B. Franks and M. Bauer (Eds.), Social Psychology of Communication. http://moodle.lse.ac.uk/file.php/151/chapter_6_jovchelovitch.pdf

[14]Kail, Robert V. \& Cavanaugh, John C. (2004). Human development: A life-span view (3rd ed.). Belmont, CA: Thomson/Wadsworth. p. 16

[15] Moscovici, S. (1961). La psychanalyse, son image et son public. Paris: Presses Universitaires de France.

[16]Moscovici, S. (1963).Attitudes and opinions. Annual Review of Psychology, 14, 231-260. 
[17]Moscovici, S. (1973). Foreword. In C. Herzlich (Ed.), Health and illness: A social psychological analysis (pp. ix-x v). London/New York: Academic Press.

[18] Slater, Charles L. (2003), "Generativity versus stagnation: An elaboration of erikson's adult stage of human development", Journal of Adult Development, 10 (1): 53-65

[19]Voelklein, C., \& Howarth, C. (2005). A Review of Controversies about Social Representations Theory: A British Debate. Culture \& Psychology, 11, 431-454.

[20]Verheggen, T., \& Baerveldt, C. (2007). We don't share! The social representation approach, enactivism and the ground for an intrinsically social psychology. Culture \& Psychology, 13(1), 5-27.

[21]Wagner, W., Farr, R., Jovchelovitch, S., Lorenzi-Cioldi, F., Marková, I., Duveen, G. \& Rose, D. (1999).Theory and method of social representations [online]. London: LSE Research Online.

[22]Walsh, S., Shulman, S. \& Maurer, O. (2008). Immigration distress, mental health status and coping among young immigratns: A 1-year follow-up study. International Journal of Intercultural Relations, 32, 371-384.

[23]Wagner, W., Mecha, A., \& Carvalho, M. d. R. (2008). Discourse and Representation in the Construction of Witchcraft. In T. Sugiman, K. Gergen, W. Wagner, \& Y. Yamada (Eds.), Meaning in Action: Constructions, Narratives and Representations. Tokyo: Springer.

[24]Wright, Jr, J. Eugene (1982). Erikson: Identity and Religion. New York, NY: Seabury Press. p. 73. 